\title{
ANALISIS BUDAYA ORGANISASI, MOTIVASI DAN KINERJA PEGAWAI (STUDI PADA PEGAWAI KANTOR SEKRETARIATDPRD KABUPATEN GUNUNGKIDUL)
}

\author{
Tri Maryati \\ Program Studi Manajemen Universitas Muhammadiyah Yogyakarta \\ e-mail : try_maryati@umy.ac.id
}

\section{INTISARI}

Penelitian ini bertujuan untuk menganalisis budaya organisasi yang diterapkan di Kantor Sekeretariat DPRD Kabupaten Gunungkidul, menganalisis faktor motivasi apa yang mendorong karyawan untuk bekerja, menganalisis uji beda kinerja karyawan dan motivasi kerja karyawan di kantor Sekretariat DPRD Kabupaten Gunungkidul ditinjau dari gender.

Obyek penelitian adalah Kantor Sekretariat DPRD Kabupaten Gunungkidul dan subyeknya adalah karyawan di Sekretariat DPRD Kabupaten Gunungkidul berjumlah 60 orang dan jenis datanya adalah data primer. Analisis data menggunakan analisis deskriptif dan uji beda ( $\mathrm{t}$ test).

Hasil analisis deskriptif bahwa budaya organisasi di Kantor Sekretariat DPRD Gunung Kidul sudah inovatif, karyawan cukup berani mengambil risiko, perhatian pada hal-hal yang detail, berfokus pada tim, mendorong pegawai untuk tidak malas-malasan dan tidak mempertahankan status quo. Faktor yang mendorong karyawan untuk bekerja di Sekretariat DPRD Gunung Kidul adalah kebutuhan untuk berkuasa, kebutuhan berafilasi dan kebutuhan untuk berprestasi tinggi, dengan faktor yang paling dominan adalah kebutuhan untuk berafiliasi, diikuti kebutuhan kebutuhan berprestasi dan kebutuhan berkuasa. Sedangkan hasil analisis uji beda, tidak terdapat perbedaan kinerja,terdapat perbedaan kebutuhan kekuasaan, tidak terdapat perbedaan kebutuhan berprestasi dan tidak terdapat perbedaan kebutuhan berafiliasi ditinjau dari gender.

Kata kunci: budaya organisasi, kebutuhan berkuasa, kebutuhan berafiliasi, kebutuhan berprestasi

\section{PENDAHULUAN}

Sekretariat Dewan Perwakilan Rakyat Daerah Kabupaten Gunungkidul mempunyai tugas dan fungsi cukup penting yaitu melaksanakan tugas-tugas birokrasi, melayani, memfasilitasi dan mendampingi para anggota DPRD. Sebagai 
organisasi pemerintah, Sekretariat DPRD Kabupaten Gunungkidul dituntut untuk mampu bekerja secara efektif, efisien dan profesional serta memiliki komitmen yang tinggi untuk memajukan organisasi. Kinerja setiap Pegawai Negeri Sipil (PNS) pada mendukung dan memberi kontribusi positif terhadap kinerja organisasi secara keseluruhan.

Dalam melaksanakan tugas, maka sekretariat DPRD memiliki Visi dan Misi yaitu: "Lembaga yang prima dalam mengaktualisasikan pelayanan berkualitas untuk mendukung Tri Fungsi DPRD”. Sesuai visi organisasi yang telah ditetpkan maka dirumuskan misi sebagai berikut :

1. Memantapkan perencanaan program kerja tahunan dalam rangka pembinaan dan pelayanan administrasi umum, Rumah Tangga dan Perlengkapan satuan kerja.

2. Memantapkan perencanaan program kerja tahunan dalam rangka pembinaan dan pelayanan Rapat-rapat/persidangan DPRD dan pembuatan Risalah Sidang.

3. Memantapkan perencanaan program kerja tahunan dalam rangka pembinaan dan pelayanan pengurusan dan pengelolaan keuangan DPRD, perencanaan anggaran dan pertanggung jawaban pengelolaan keuangan DPRD.

4. Memantapkan koordinasi perencanaan Bantuan Kelompok Pakar/Tenaga Ahli.

5. Memantapkan koordinasi perencanaan Sistem Komunikasi Digital (Communications Digital System) secara terpadu.

Visi dan misi di atas akan bisa tercapai kalau di dukung oleh semua pegawai yang ada di dalamnya diantaranya adalah kinerja yang tinggi, motivasi yang tinggi dari pegawai, kepemimpinan yang krestif dan inovatif dan di dukung oleh budaya yang inovatif.

Gomes, Faustino Cardoso (2010)menyatakan bahwa kinerja: " The record of outcames produced on a spesified job function or activity during a spesified time period". Menurut Ancok (2012) mengungkapkan bahwa budaya organisasi berperan sebagai 
perekat sosial yang mendekatkan antar anggota organisasi karena adanya pemahaman yang sama (shared meanings) tentang bagaimana anggota organisasi harus berperilaku. Sebagaimana diungkapkan oleh Kreiner dan Kinicki (dalam Ancok, 2012) budaya organisasi merupakan pemersatu organisasi dan mengikat anggota organisasi melalui nilai-nilai yang diyakini, serta simbol yang mengandung cita-cita sosial bersama yang ingin dicapai. Sedangkan menurut Tjahjono (2004) budaya organisasi merupakan konsep penting yang berperan dalam meningkatkan kinerja organisasi. Budaya organisasi yang mengabaikan aspek keadilan berpotensi menyebabkan kinerja yang fungsional (Palupi \& Tjahjono, 2016).

Teori motivasi yang dikembangkan oleh Mc Clelland dalam Robbins (2015) yang menyatakan bahwa pencapaian, kekuasaan, dan afiliasi adalah tiga kebutuhan penting dan dapat membantu dalam menjelaskan motivasi. Teori kebutuhan dikembangkan oleh David 'McClelland dan rekan-rekannya bahwa dalam diri kita ada tiga kebutuhan yaitu need for power (Kebutuhan Kekuasaan), need for Affilition (Kebutuhan Berafiliasi), dan need for achievement (Kebutuhan Berprestasi).

Banyak kajian sudah dilakukan terkait dengan budaya organisasi, kepemimpinan, motivasi dan kinerja di organisasi maupun perusahaan tetapi masih sedikit yang mengkaji tentang budaya organisasi, kepemimpinan transformasional dan kinerja di birokrasi. Penelitian Tukijan dan Hasrnoto berjudul Analisis perbedaan kecerdasan emosional, motivasi kerja dan kinerja ditinjau dari gender dan tingkat pendidikan (Studi Faskel Ekonomi PNPM mandiri Perkotaan Jawa Tengah, diperoleh kesimpulan bahwa Motivasi Kerja faskel laki-laki dan faskel perempuan berbeda. Kinerja faskel laki-laki dan perempuan berbeda. Penelitian Caroline Pudjowibowo berjudul Perbedaan Motivasi, Kepuasan Kerja, Keinginan berpindah kerja, dan Persepsi deskriminasi antara auditor pria dan wanita pada KAP di kota Semarang, diperoleh kesimpulan tidak ada perbedaan dalam motivasi dan keinginan berpindah, tetapi ada beda dalam kepuasan kerja sertapenelitian Muslimin (2006), dalam penelitiannya Perbedaan Gaya Kepemipinan dan Kinerja antara auditor pria dan wanita pada Kantor Akuntan Publik di Wilayah Surabaya 
Timur, diperoleh kesimpulan bahwa terdapat perbedaan Gaya Kepemimpinan dan Kinerja Auditor wanita pada kantor Akuntan Publik di Wilayah Surabaya.

Dalam penelitian ini dibatasi pada: (1) analisis deskriptif terkait dengan kinerja, persepsi karyawan terhadap budaya organisasi, persepsi karyawan terhadap motivasi; (2) uji beda kinerja dan motivasi kerja pegawai dilihat dari jenis kelamin.

\section{KAJIANTEORI}

\section{Kinerja}

Gomes (2006) menyatakan bahwa kinerja: " The record of outcames produced on a spesified job function or activity during a spesified time period". Hal tersebut dapat dijelaskan bahwa kinerja merupakan catatan outcame yang dihasilkan dari sebuah pekerjaan khusus tertentu atau kegiatan selama periode waktu tertentu.

Pengukuran kinerja pegawai mengacu pada pendapat yang dikemukakan oleh Gomez (2006) sebagai berikut: 1) Quality of Work (kualitas kerja) ; 2). Quantity of Work (kuantitas kerja); 3). Job Knowledge (pengetahuan pekerjaan); 4). Creativeness (kratifitas); 5). Cooperative (kerjasama); 6). Initiative (inisiatif); 7). Dependerability (ketergantungan) dan 8). Personal Quality (kualitas personil).

\section{Budaya Organisasi}

Definisi budaya organisasi yang disampaikan oleh Amstrong (dalam Ancok, 2012) "Organizational or corporate culture is the pattern of values, norms, beliefs, attitudes, and assumptions that may not have been articulated but shape the ways in which people behave and things get done. Values refer to what is believed to be important about how people and the organizations behave. Norms are the unwritten rules of behaviour".

Menurut Robbins (2015) mengemukakan ada tujuh komponen yang dapat dijadikan indikator dalam mengukur budaya organisasi. Indikator tersebut adalah sebagai berikut:

1) Keberanian berinovasi dan mengambil resiko.

2) Perhatian terhadap hal yang detail. 
3) Berorientasi pada hasil.

4) Berorientasi pada kemanusiaan.

5) Berfokus pada kerja tim.

6) Agresivitas pegawai dalam berkarya.

7) Stabilitas.

\section{Motivasi}

Teori motivasi yang dikembangkan oleh Mc Clelland dalam Robbins(2015) yang menyatakan bahwa pencapaian, kekuasaan, dan afiliasi adalah tiga kebutuhan penting dan dpat membantu dalam menjelaskan motivasi.Teori kebutuhandikembangkan oleh David 'McClelland dan rekan-rekannya bahwa dalam diri kita ada tiga kebutuhan yaitu :

1) Need for Power (Kebutuhan Kekuasaan /nPow) yaitu kebutuhan untuk membuat orang lain berperilaku dalam suatu cara, dimana orang-orang itu tanpa dipaksa tidak akan berperilaku demikian, atau suatu bentuk ekspresi dari individu untuk mengendalikan dan mempengaruhi orang lain.

2) Need for affiliation (Kebutuhan Berafiliasi/nAff) yaitu kebutuhan untuk membuat orang lain berperilaku dengan cara yang tidak akan dilakukan tanpa dirinya.

3) Need of achievement (Kebutuhan Berprestasi/nAch)yaitu merupakan dorongan untuk mengungguli, berprestasi sehubungan dengan seperangkat standar, bergulat untuk sukses.

\section{Hipotesis}

Dalam persepsi peneliti pada dasarnya kinerja perempuan berbeda dengan laki-laki,kaum perempuanlebih teliti dalam bekerja dibandingkan dengan kaum laki-laki. Hasil penelitian empiris yang dilakukan oleh Tukijan dan Hasrnoto, dalam penelitiannya berjudul Analisis perbedaan kecerdasan emosional, motivasi kerja dan kinerja ditinjau dari gender dan tingkat pendidikan (Studi Faskel Ekonomi PNPM 
mandiri Perkotaan Jawa Tengah, diperoleh kesimpulan Kinerja faskel laki-laki dan perempuan berbeda. Disamping itu kajian empiris yang dilakukan oleh Muslimin (2006), dalam penelitiannya Perbedaan Gaya Kepemipinan dan Kinerja antara auditor pria dan wanita pada Kantor Akuntan Publik di Wilayah Surabaya Timur, diperoleh kesimpulan bahwa terdapat perbedaan Kinerja Auditor wanita dan pria pada kantor Akuntan Publik di Wilayah Surabaya.

Dari uraian di atas maka dapat dirumuskan hipotesis sebagai berikut :

H1 : Terdapat perbedaan kinerja antara karyawan laki-laki dan perempuan di Kantor Sekretariat DPRD Kabupaten Gunungkidul.

Dalam persepsi peneliti bahwa motivasi untuk bekerja antara kaum laki-laki dan perempuan berbeda. Dalam hal kebutuhan akan kekuasan kaum laki-laki lebih tinggi kemauan untuk berkuasa dibandingkan dengan perempuan. Dalam hal kebutuhan afiliasi perempuan lebih tinggi daripada laki-laki, sedangkan dalam hal kebutuhan untuk berprestasi laki-laki juga lebih tinggi untuk mencapai prestasi yang tinggi dibandingkan dengan perempuan. Kajian empiris yang dilakukan Tukijan dan Hasrnoto, dalam penelitiannya berjudul Analisis perbedaan kecerdasan emosional, motivasi kerja dan kinerja ditinjau dari gender dan tingkat pendidikan (Studi Faskel Ekonomi PNPM mandiri Perkotaan Jawa Tengah, diperoleh kesimpulan bahwa Motivasi Kerja faskel laki-laki dan faskel perempuan berbeda.

Dari uraian di atas maka diturunkan hipotesis sebagai berikut :

H2: Terdapat perbedaan motivasi kerja karyawan antara karyawan laki-laki dan perempuan di Kantor Sekretariat DPRD Kabupaten Gunungkidul.

\section{METODE PENELITIAN}

\section{Subyek, obyek dan sampel penelitian}

Obyek penelitian ini adalah di sekretariat DPRD Kabupaten Gunungkidul. Subyek penelitian ini adalah keseluruhan pegawai pada sekretariat DPRD Kabupaten Gunungkidul dengan jumlah pegawai seluruhnya adalah 60 orang. 
Sampel dalam penelitian ini seluruh pegawai pada Sekretariat DPRD Kabupaten Gunungkidul.

\section{Definisi Operasional Variabel}

\section{Tabel 1. Definisi Operasional Variabel Penelitian}

\begin{tabular}{|c|c|}
\hline Variabel & Indikator \\
\hline $\begin{array}{l}\text { Budaya Organisasi diartikan seperangkat } \\
\text { nilai-nilai, keyakinan, sikap, dan tradisi } \\
\text { bersama yang mengikat anggota } \\
\text { organisasi sebagai acuan untuk bekerja } \\
\text { dan berinteraksi antarsesama anggota } \\
\text { organisasi. }\end{array}$ & $\begin{array}{l}\text { Tujuh komponen budaya organisasi } \\
\text { menurut Robbins (2015) dalam Ancok } \\
\text { (2012) sebagai berikut: } \\
\text { 1. Keberanian berinovasi dan } \\
\text { mengambil resiko } \\
\text { 2. Perhatian terhadap hal yang detail } \\
\text { 3. Berorientasi pada hasil } \\
\text { 4. Berorientasi pada kemanusiaan } \\
\text { 5. Berfokus pada kerja tim } \\
\text { 6. Agresifitas karyawan dalam } \\
\text { berkarya } \\
\text { 7. Stabilitas }\end{array}$ \\
\hline $\begin{array}{l}\text { Motivasi } \\
\text { Robbins (2015) mengemukakan bahwa } \\
\text { motivasi adalah keinginan untuk } \\
\text { melakukan sebagai kesediaan untuk } \\
\text { mengeluarkan tingkat upaya yang } \\
\text { tinggiuntuk tujuan-tujuan organisasi, } \\
\text { yang dikondisikan oleh kemampuan } \\
\text { upaya itu untuk memenuhi suatu } \\
\text { kebutuhan individual. }\end{array}$ & $\begin{array}{l}\text { Teori yang dikembangkan oleh Mc } \\
\text { Cleland dalam Robbins (2015) yang } \\
\text { menyatakan bahwa seseorang } \\
\text { mempunyai tiga jenis kebutuhan yaitu } \\
\text { "need for achievement (nAch), need for } \\
\text { power (nPo) dan need for Affilition } \\
\text { (nAff)". }\end{array}$ \\
\hline $\begin{array}{l}\text { Kinerja. } \\
\text { Gomes (2010) menyatakan bahwa kinerja: } \\
\text { " The record of outcames produced on a } \\
\text { spesified job function or activity during a } \\
\text { spesified time period". Hal tersebut dapat } \\
\text { dijelaskan bahwa kinerja merupakan } \\
\text { catatan outcame yang dihasilkan dari } \\
\text { sebuah pekerjaan khusus tertentu atau } \\
\text { kegiatan selama periode waktu tertentu. }\end{array}$ & $\begin{array}{l}\text { Pengukuran kinerja pegawai mengacu } \\
\text { pada pendapat yang dikemukakan oleh } \\
\text { Gomez (2010) sebagai berikut: } \\
\text { 1. Quality of Work (kualitas kerja) } \\
\text { 2. Quantity of Work (kuantitas kerja) } \\
\text { 3. Job Knowledge (pengetahuan } \\
\quad \text { pekerjaan) } \\
\text { 4. Creativeness (kratifitas) } \\
\text { 5. Cooperative (kerjasama) } \\
\text { 6. Initiative (inisiatif) } \\
\text { 7. Dependerability (ketergantungan) } \\
\text { 8. Personal Quality (kualitas personil) }\end{array}$ \\
\hline
\end{tabular}




\section{Uji Kualitas instrumen}

1) Uji Validitas

Validitas penelitian menggambarkan kemampuan indikator mengukur konsep yang hendak diukur (Tjahjono,2015). Uji keabsahan (validity) menggunakan korelasi Person Product Moment. Suatu pertanyaan dinyatakan valid apabila nilai sig. < 0,05 (Sekaran, 2013).

2) Uji Reliabilitas

Sebagai dasar untuk menentukan reliabel atau tidaknya kuesioner adalah nilai koefisien Cronbach's alpha (Cronbach's alpha reliability coeficients) dari variabelvariabel yang terlibat dalam penelitian ini. Jika nilai cronbach's alpha berada pada kisaran 0,6 sampai dengan 1, maka kuesioner dinyatakan reliabel, sebaliknya jika nilai lebih kecil daripada 0,6 maka tersebut dinyatakan tidak reliabel (Sekaran, 2013)

\section{Analisis Data}

1) Analisis Deskriptif

Analisis ini digunakan untuk memberikan gambaran atau deskripsi empiris atas data yang dikumpulkan dalam penelitian. Statistik deskriptif ini digunakan untuk menggambarkan rata-rata nilai item setiap variabel yang diteliti (Sekaran, 2013).

2) Analisis Uji beda.

Analisis yang digunakan adalah Statistik non parametrik yaitu menggunakan uji $\mathrm{t}$ untuk mengetahui apakah ada perbedaan kinerja karyawan ditinjau dari gender.

- Jika nilai signifikansi (2-tailed) > 0,05 maka tidak terdapat perbedaan antara kedua kelompok

- Jika nilai signifikansi (2-tailed) < 0,05 maka terdapat perbedaan antara kedua kelompok 


\section{ANALISIS DATA}

\section{Analisis Deskriptif}

Profil responden berdasarkan jenis kelamin dan usia adalah sebagai berikut :

Tabel 2. Karakteristik Responden berdasarkan jenis kelamin

\begin{tabular}{|c|l|c|c|}
\hline No & Jenis Kelamin & Jumlah & Persentase \\
\hline 1 & Laki-laki & 48 & 80 \\
\hline 2 & Perempuan & 12 & 20 \\
\hline \multicolumn{2}{|c|}{ Total } & $\mathbf{6 0}$ & $\mathbf{1 0 0}$ \\
\hline
\end{tabular}

Dari tabel 2, dapat dilihat bahwa jumlah responden pegawai laki-laki pada Sekretariat DPRD Kabupaten Gunungkidul lebih dominan yaitu sebesar 80 persen, sedangkan jumlah perempuan sebesar 20 persen.

Tabel 3. Karakteristik Responden berdasarkan usia

\begin{tabular}{|c|l|c|c|}
\hline No & Kelompok Usia (Tahun) & Jumlah (orang) & Persentase (\%) \\
\hline 1 & $\geq 20$ & 0 & 0 \\
\hline 2 & $21-30$ & 7 & 11,66 \\
\hline 3 & $31-40$ & 22 & 36,66 \\
\hline 4 & $41-50$ & 18 & 30 \\
\hline 5 & $<50 \quad$ Jumlah & 13 & 21,66 \\
\hline \multicolumn{2}{|c|}{}
\end{tabular}

Data tabel 3 tersebut memperlihatkan bahwa usia responden yang berusia antara 31 - 40 tahun lebih dominan yakni sebesar 36,66 persen dibandingkan usia responden lainnya. Responden yang paling muda memiliki usia 23 tahun dan yang paling tua berusia 58 tahun.

\section{Analisis Deskriptif.}

Hasil analisis deskriptif data skor Budaya Organisasi, kepemimpinan, motivasi dan kinerja adalah sebagai berikut : 
Tabel 4. Distribusi Frekuensi Data Skor Budaya Organisasi

\begin{tabular}{|c|c|c|}
\hline No & Pernyataan & Mean \\
\hline 1 & Pegawai termotivasi untuk menjadi kreatif dan inovatif & 4.20 \\
\hline 2 & $\begin{array}{l}\text { Pegawai termotivasi untuk mencoba hal baru (berani mengambil } \\
\text { resiko) }\end{array}$ & 2.73 \\
\hline 3 & Pegawai menjalankan pekerjaanya dengan cermat & 4.18 \\
\hline 4 & $\begin{array}{l}\text { Pegawai menjalankan pekerjaan secara detail atau sampai ke hal-hal } \\
\text { kecil }\end{array}$ & 4.12 \\
\hline 5 & Pegawai selalu menjaga kualitas pekerjaan dengan baik. & 4.47 \\
\hline 6 & $\begin{array}{l}\text { Pegawai termotivasi untuk menghasilkan keluaran (output) dari } \\
\text { sebuah pekerjaan yang berkualitas }\end{array}$ & 4.40 \\
\hline 7 & $\begin{array}{l}\text { Pegawai termotivasi untuk menghasilkan keluaran (output) dari } \\
\text { sebuah pekerjaan yang berjumlah banyak }\end{array}$ & 3.67 \\
\hline 8 & Pegawai bebas melakukan pekerjaannya dengan caranya sendiri & 2.18 \\
\hline 9 & $\begin{array}{l}\text { Organisasi memposisikan pegawai sebagai anggota organisasi yang } \\
\text { terhormat }\end{array}$ & 4.07 \\
\hline 10 & $\begin{array}{l}\text { Organisasi selalu mempertimbangkan segala keputusan agar tidak } \\
\text { merugikan pegawai }\end{array}$ & 4.28 \\
\hline 11 & $\begin{array}{l}\text { Organisasi selalu merancang job desk (beban kerja) dengan basis } \\
\text { kelompok (team work) }\end{array}$ & 3.98 \\
\hline 12 & $\begin{array}{l}\text { Struktur organisasi yang ada menekankan pada organisasi berbasis } \\
\text { tim }\end{array}$ & 4.08 \\
\hline 13 & $\begin{array}{l}\text { Organisasi selalu mampu membuat pegawai bergairah untuk terus } \\
\text { berprestasi }\end{array}$ & 4.13 \\
\hline 14 & $\begin{array}{l}\text { Organisasi selalu mampu membuat pegawai tidak malas-malasan } \\
\text { untuk bekerja }\end{array}$ & 4.18 \\
\hline 15 & $\begin{array}{l}\text { Organisasi selalu berusaha untuk maju dan berkembang dengan } \\
\text { mengubah kondisi yang ada kearah yang lebih baik atau tidak } \\
\text { mempertahankan status quo }\end{array}$ & 3.95 \\
\hline & Rata-rata mean & 3,90 \\
\hline
\end{tabular}

Dari hasil analisis pada tabel di atas bahwa :

a. Oganisasi telah memotivasi pegawai untuk giat melakukan inovasi dan merangsang pegawai untuk berani mengambil resiko dengan rata-rata jawaban 4,20 .

b. Pegawai untuk lebih cermat, memberikan perhatian pada detail, dan menjaga kualitas secara menyeluruh sampai ke hal-hal yang kecil, hal ini ditunjukkan dari jawaban pegawai dengan nilai mean diatas 4 . 
c. Pegawai sudah termotivasi untuk menghasilkan keluaran (output) dari sebuah pekerjaan yang berkualitas dengan nilai mean 4.4, pegawai bebas melakukan pekerjaannya dengan caranya sendiri masih rendah yaitu dengan nilai mean 2.18 .

d. Organisasi memposisikan pegawai sebagai anggota organisasi yang terhormat dengan nilai mean 4.07 dan organisasi selalu mempertimbangkan segala keputusan agar tidak merugikan pegawai dengan nilai mean 4.8.

e. Organisasi selalu merancang job desk (beban kerja) dengan basis kelompok (team work) dengan nilai mean 3.98 dan Struktur organisasi yang ada menekankan pada organisasi berbasis tim dengan nilai mean 4.08.

f. Organisasi selalu mampu membuat pegawai bergairah untuk terus berprestasi dengan nilai mean 4.13 dan organisasi selalu mampu membuat pegawai tidak malas-malasan untuk bekerja dengan nilai mean 4.18.

g. Organisasi selalu berusaha untuk maju dan berkembang dengan mengubah kondisi yang ada kearah yang lebih baik atau tidak mempertahankan status quo dengan nilai mean 3.95 .

\section{Deskripsi Data Kebutuhan Berkuasa (Need for Power)}

Hasil analisis deskripsi data skor Kebutuhan Berkuasa (Need for Power) dapat dilihat pada Tabel 5.

Tabel 5. Distribusi Frekuensi Data Skor Kebutuhan Berkuasa (Need for Power)

\begin{tabular}{|c|l|c|}
\hline No & \multicolumn{1}{|c|}{ Pernyataan } & Mean \\
\hline 1 & $\begin{array}{l}\text { Saya selalu berusaha agar teman-teman menjalankan ide-ide saya } \\
\text { dalam bekerja }\end{array}$ & 3.15 \\
\hline 2 & $\begin{array}{l}\text { Saya senang menjelaskan masalah pekerjaan kepada teman-teman } \\
\text { sehingga mereka dapat menjalankan pekerjaan mereka dengan baik }\end{array}$ & 3.83 \\
\hline 3 & $\begin{array}{l}\text { Saya senang memberikan inspirasi produktif kepada teman-teman } \\
\text { saya }\end{array}$ & 4.12 \\
\hline 4 & $\begin{array}{l}\text { Saya senang mengarahkan teman-teman sehingga mereka bekerja } \\
\text { lebih baik }\end{array}$ & 3.52 \\
\hline 5 & Saya sering memberi arahan kepada teman-teman mengenai & 3.28 \\
\hline
\end{tabular}




\begin{tabular}{|c|l|c|}
\hline No & \multicolumn{1}{|c|}{ Pernyataan } & Mean \\
\hline & pekerjaan yang dilakukan & \\
\hline & Rata-rata Mean & 3,58 \\
\hline
\end{tabular}

Dari tabel di atas dapat dilihat bahwa kebutuhan berkuasa karyawan di Sekretariat DPRD Gunung Kidul tinggi, hal ini bisa di lihat dari nilai mean sebesar 3.58 .

\section{Deskripsi Data Kebutuhan Berafiliasi (Need for Affiliation)}

Hasil analisis deskriptif data skor Kebutuhan Berafiliasi (Need for Affiliation) dapat dilihat pada tabel 6 .

Tabel 6. Distribusi Frekuensi Data Skor Kebutuhan Berafiliasi (Need for

\section{Affiliation)}

\begin{tabular}{|c|l|c|}
\hline No & \multicolumn{1}{|c|}{ Pernyataan } & Mean \\
\hline 1 & Saya selalu berusaha menjaga hubungan baik dengan teman kerja saya & 4.27 \\
\hline 2 & Saya senang bekerja bersama-sama teman saya dalam & 4.33 \\
\hline 3 & $\begin{array}{l}\text { Saya menyukai berbagai pengetahuan dengan teman-teman } \\
\text { pekerjaan }\end{array}$ & $\begin{array}{l}\text { Saya senang mendapat dukungan dari teman-teman dalam } \\
\text { mengerjakan pekerjaan }\end{array}$ \\
\hline 5 & Dalam bekerja, saya senang dengan sikap saling menghargai & 4.43 \\
\hline & Rata-rata Mean & 4,28 \\
\hline
\end{tabular}

Dari tabel di atas dapat dilihat bahwa kebutuhan untuk berafiliasi karyawan di Sekretariat DPRD Gunung Kidul tinggi, hal ini bisa di lihat dari nilai mean sebesar 4,28 .

\section{Deskripsi Data Kebutuhan Berprestasi (Need for Achievement)}

Hasil analisis deskriptif data skor Kebutuhan Berprestasi (Need for Achievement) dapat dilihat pada Tabel 7. 
Tabel 7. Distribusi Frekuensi Data Skor Kebutuhan Berprestasi (Need for

Achievement)

\begin{tabular}{|c|l|c|}
\hline No & \multicolumn{1}{|c|}{ Pernyataan } & Mean \\
\hline 1 & $\begin{array}{l}\text { Saya suka mengerjakan pekerjaan yang memiliki resiko moderat atau } \\
\text { sedang }\end{array}$ & 2.97 \\
\hline 2 & Saya yakin bahwa keberhasilan pekerjaan saya ditentukan saya sendiri & 4.02 \\
\hline 3 & $\begin{array}{l}\text { Saya menyukai saat hasil pekerjaan yang saya lakukan dinilai atasan } \\
\text { saya }\end{array}$ & 4.10 \\
\hline 4 & $\begin{array}{l}\text { Masukan orang lain terhadap hasil kerja saya adalah hal yang saya } \\
\text { inginkan }\end{array}$ & 4.32 \\
\hline & \multicolumn{1}{|c|}{3,85} \\
\hline
\end{tabular}

Dari tabel di atas dapat dilihat bahwa kebutuhan berprestasi karyawan di Sekretariat DPRD Gunung Kidul tinggi, hal ini bisa di lihat dari nilai mean sebesar 3,85 .

Dari hasil analisis di atas di mana hasil jawaban rata-rata reponden tinggi, maka dapat disimpulkan bahwa faktor yang mendorong karyawan untuk bekerja di Sekretariat DPRD Gunung Kidul adalah kebutuhan untuk berkuasa, kebutuhan berafilasi dan kebutuhan untuk berprestasi, dengan faktor yang paling dominan adalah kebutuhan untuk berafiliasi, diikuti kebutuhan berprestasi dan kebutuhan berkuasa.

\section{Kinerja Pegawai}

Hasil analisis deskriptif data skor kinerja pegawai dapat dilihat pada Tabel 8.

Tabel 8.Distribusi Frekuensi Data Skor Kinerja Pegawai

\begin{tabular}{|c|l|c|}
\hline No & \multicolumn{1}{|c|}{ Pernyataan } & Mean \\
\hline 1 & $\begin{array}{l}\text { Pegawai bekerja dengan target kualitas yang telah ditetapkan } \\
\text { perusahaan }\end{array}$ & 4.30 \\
\hline 2 & $\begin{array}{l}\text { Pegawai dapat menyelesaikan beberapa pekerjaan dalam waktu } \\
\text { singkat }\end{array}$ & 4.00 \\
\hline 3 & $\begin{array}{l}\text { Pegawai mampu melaksanakan pekerjaan saya tanpa banyak } \\
\text { dijelaskan pimpinan atau rekan kerja }\end{array}$ & 4.25 \\
\hline 4 & Pegawai mengembangkan kreativitas saya dalam bekerja & 4.40 \\
\hline 5 & Pegawai mampu menjalin kerjasama dengan rekan kerja pada saat & 4.35 \\
\hline
\end{tabular}




\begin{tabular}{|c|l|c|}
\hline No & \multicolumn{1}{|c|}{ Pernyataan } & Mean \\
\hline & bekerja & \multicolumn{1}{|c|}{} \\
\hline 6 & $\begin{array}{l}\text { Pegawai berinisiatif melakukan pekerjaan lain bila sudah selesai } \\
\text { mengerjakan sebuah pekerjaan }\end{array}$ & 4.00 \\
\hline 7 & $\begin{array}{l}\text { Pegawai tidak tergantung pada rekan kerja dalam melakukan suatu } \\
\text { pekerjaan }\end{array}$ & 3.13 \\
\hline 8 & $\begin{array}{l}\text { Pegawai mempunyai kemampuan dan kompetensi yang memadai } \\
\text { dalam melakukan pekerjaan saya }\end{array}$ & 4.10 \\
\hline 9 & Pegawai mempunyai kecakapan dalam menggunkan alat kerja & 3.68 \\
\hline 10 & Pegawai melaksanakan jadwal kerja sesuai peraturan yang berlaku & 4.15 \\
\hline 11 & Pegawai mempunyai tingkat kehadiran tinggi ditempat kerja & 4.22 \\
\hline 12 & Pegawai mempunyai kemampuan berkomunikasi dengan atasan & 4.07 \\
\hline 13 & $\begin{array}{l}\text { Pegawai mempunyai kemampuan dalam memberikan bimbingan dan } \\
\text { penjelasan kepada rekan kerja }\end{array}$ & 3.43 \\
\hline 14 & Pegawai teliti dalam melakukan setiap pekerjaan & 4.00 \\
\hline 15 & Pegawai mempunyai kemampuan berkomunikasi dengan rekan kerja & 4.18 \\
\hline & Rata-rata & 3,95 \\
\hline
\end{tabular}

Dari tabel di atas memperlihatkan bahwa skor kinerja rata-rata pegawai 3,95 artinya kinerja karyawan tergolong tinggi.

\section{Analisis Uji Beda}

Analisis yang digunakan adalah Statistik non parametrik yaitu menggunakan uji $\mathrm{t}$ untuk mengetahui apakah ada perbedaan kinerja karyawan ditinjau dari gender.

- Jika nilai signifikansi (2-tailed) $>0,05$ maka tidak terdapat perbedaan antara kedua kelompok

- Jika nilai signifikansi (2-tailed) $<0,05$ maka terdapat perbedaan antara kedua kelompok

Berikut adalah analisis uji beda untuk variabel kinerja, kebutuhan berprestasi, kebutuhan kekuasaan dan kebutuhan berafiliasi. 
a. Variabel Kinerja

Tabel 9. Uji beda kinerja karyawan

\begin{tabular}{|l|l|l|l|l|l|}
\hline & \multicolumn{2}{|l|}{$\begin{array}{l}\text { Levene's Test for Equality } \\
\text { of Variance }\end{array}$} & \multicolumn{2}{l|}{$\begin{array}{l}\text { t-test for Equality of } \\
\text { Means }\end{array}$} \\
\hline & F Sig. & t & df & $\begin{array}{l}\text { Sig.(2- } \\
\text { tailed) }\end{array}$ \\
\hline $\begin{array}{l}\text { JML Equal variance } \\
\text { assumted } \\
\begin{array}{l}\text { Equal variance non } \\
\text { assumted }\end{array}\end{array}$ & 1.686 & 0,199 & $-0,548$ & 58 & 0,586 \\
\hline
\end{tabular}

Berdasarkan output di atas, diperoleh nilai Sig. (2-tailed) sebesar 0,568>0,05, maka sesuai dengan dasar pengambilan keputusan dalam uji independent sample TTest, maka dapat disimpulkan bahwa tidak terdapat perbedaan antara variabel kinerja pada kelompok pria dan wanita.

b. Variabel Kekuasaan.

Tabel 10.Uji beda kebutuhan kekuasaan

\begin{tabular}{|l|l|l|l|l|l|}
\hline & \multicolumn{4}{|l|}{$\begin{array}{l}\text { Levene's Test for Equality of } \\
\text { Variance }\end{array}$} & $\begin{array}{l}\text { t-test for } \\
\text { Means }\end{array}$ \\
\hline & F & Sig. & $\mathbf{t}$ & df & $\begin{array}{l}\text { Sig.(2- } \\
\text { tailed) }\end{array}$ \\
\hline $\begin{array}{l}\text { JML Equal variance } \\
\text { assumted } \\
\begin{array}{l}\text { Equal variance non } \\
\text { assumted }\end{array}\end{array}$ & 0,424 & 0,517 & - & 58 & 0,007 \\
& & 2,814 & 17,663 & 0.007 \\
\hline
\end{tabular}

Berdasarkan output di atas, diperoleh nilai Sig. (2-tailed) sebesar 0,007<0,05, maka sesuai dengan dasar pengambilan keputusan dalam uji independent sample TTest, maka dapat disimpulkan bahwa terdapat perbedaan antara variabel kebutuhan kekuasaan kelompok pada pria dan wanita. 
c. VariabelKebutuhanBerprestasi

Tabel 11. Uji beda kebutuhan berprestasi

\begin{tabular}{|l|l|l|l|l|l|l|}
\hline & & \multicolumn{2}{|l|}{$\begin{array}{l}\text { Levene's Test for Equality } \\
\text { of Variance }\end{array}$} & \multicolumn{2}{l|}{$\begin{array}{l}\text { t-test for Equality of } \\
\text { Means }\end{array}$} \\
\hline & F & Sig. & t & df & $\begin{array}{l}\text { Sig.(2- } \\
\text { tailed) }\end{array}$ \\
\hline $\begin{array}{l}\text { JML Equal variance } \\
\text { assumted } \\
\begin{array}{l}\text { Equal } \\
\text { nonassumted }\end{array}\end{array}$ & 0,693 & 0,408 & $-0,494$ & 58 & 0,623 \\
\hline
\end{tabular}

Berdasarkan output di atas, diperoleh nilai Sig. (2-tailed) sebesar 0,623>0,05, maka sesuai dengan dasar pengambilan keputusan dalam uji independent sample TTest, maka dapat disimpulkan bahwa tidak terdapat perbedaan antara variabel kebutuhan berprestasi pada kelompok pria dan wanita.

d. Variabel Kebutuhan Berafiliasi

Tabel 12. Uji beda kebutuhan berafiliasi

\begin{tabular}{|c|c|c|c|c|c|}
\hline & \multicolumn{2}{|c|}{$\begin{array}{l}\text { Levene's Test for Equality of } \\
\text { Variance }\end{array}$} & \multicolumn{3}{|c|}{$\begin{array}{l}\text { t-test for Equality of } \\
\text { Means }\end{array}$} \\
\hline & $\mathbf{F}$ & Sig. & $t$ & df & $\begin{array}{l}\text { Sig.(2- } \\
\text { tailed) }\end{array}$ \\
\hline $\begin{array}{l}\text { JML Equal variance } \\
\text { assumted } \\
\text { Equal variance non } \\
\text { assumted }\end{array}$ & 1,412 & 0,240 & $\begin{array}{l}- \\
1,305 \\
- \\
1,722\end{array}$ & $\begin{array}{l}58 \\
27,273\end{array}$ & $\begin{array}{l}0,197 \\
0.096\end{array}$ \\
\hline
\end{tabular}

Berdasarkan output di atas, diperoleh nilai Sig. (2-tailed) sebesar 0,197>0,05, maka sesuai dengan dasar pengambilan keputusan dalam uji independent sample TTest, maka dapat disimpulkan bahwa tidak terdapat perbedaan antara variabel kebutuhan berafiliasi pada kelompok pria dan wanita. 


\section{PEMBAHASAN}

Dari aspek budaya, pertama bahwa pegawai di lingkungan sekretarian DPRD Gunung Kidul kurang berani untuk mencoba hal-hal yang baru (berani mengambil risiko), hal ini mungkin disebabkan karena mereka adalah PNS di mana semua tugas sudah digariskan dari atas dan mereka hanya tinggal melakukannya. Hasil temuan kedua bahwa pegawai dalam menjalankan tugasnya tidak ada kebebasan dalam menjalankan tugasnya. Hal ini mungkin disebabkan karena ini adalah organisasi pemerintahan sehingga dalam menjalankan tugasnya harus sesuai dengan petunjuk pelaksanaan tugas yang sudah diatur oleh pemerintah yang sifatnya tidak fleksibel.

Ketiga, pegawai sudah termotivasi untuk kreatif dan inovatif, namun organisasi harus tetap senantiasa mendorong pegawai untuk lebih kreatif dan inovatif. Seruan untuk selalu kreatif dan inovatif ada dalam Al Qur'an : ... sesungguhnya Allah tidak akan mengubah keadaan suatu kaum sebelum mereka mengubah keadaan diri mereka sendiri... (Q.S. ar-Ra'd/13: 11)

Keempat, organisasi telah berhasil meminta kepada pegawai untuk lebih cermat,memberikan perhatian pada detail, dan menjaga kualitas secara menyeluruh sampai ke hal-hal yang kecil. Hal ini sangat penting bagi organisasi sebagai pelayan masyarakat yang ingin tetap eksis, apalagi di era sekarang organisasi harus mampu untukmenciptakan Good Corporate Governance. Seruan untuk selalu bekerja dengan teliti ada dalam Al Qur'an : "Wahai orang-orang yang beriman! Apabila dikatakan kepadamu, "Berilah kelapangan di dalam majelis-majelis," maka lapangkanlah, niscaya Allah akan member kelapangan untukmu. Dan apabila dikatakan, "berdirilah kamu," maka berdirilah, niscaya Allah akan mengangkat (derajat) orang-orang yang beriman diantaramu dan orang-orang yang diberi ilmu beberapa derajat. Dan Allah maha teliti apa yang kamu kerjakan (Q.S. al-Mujadilah (58):11)

Kelima, organisasi sudah berhasil merangsang karyawan untuk berorientasi pada hasil walaupun belum optimal, sehingga organisasi harus senantiasa memotivasi kepada karyawan untuk bisa mencapai hasil yang optimal. Untuk itu 
perlu adanya rangsangan untuk karyawan yang berprestasi perlu adanya renumerasi dan bagi karyawan yang bekerja asal-asalan dan tidak profesional sehingga tidak bisa mencapai hasil seperti yang diharapkan oleh organisasi perlu adanya punishment.

Keenam, organisasi sudah berorientasi kemanusaiaan, organisasi sudah memposisikan pegawai sebagai anggota organisasi yang terhormat dan organisasi selalu mempertimbangkan segala keputusan agar tidak merugikan pegawai. Hal ini jika dilkakukan terus akan memberikan kepuasan kerja bagi pegawai, yang dampaknya nanti adalah akan meningkatkan kinerjanya.

Ketujuh, organisasi sudah merancang pekerjaan yang berbasis kelompok, dan struktur organisasi menekankan pada organisasi berbasis tim. Hal ini sangat penting, dengan kerja secara tim akan menghasilkan kinerja yang optimal, alasannya adalah dalam kerja secara tim akan terjadi sinergi diantara individu dalam kelompok tersebut, akan terjadi saling tolong menolong manakala dalam kelompok tersebut ada anggota kelompok yang mempunyai kekurangan atau tidak mampu mengerjakan beban kerja yang diberikan kepadanya.

Kedelapan, organisasi sudah mampu membuat pegawai bergairah untuk terus berprestasi dan tidak bermalas-malasan. Hal ini tentunya perlu untuk ditingkatkan untuk selalu berprestasi dan tidak bermalas-malasan karena ini adalah tuntutan dari masyakarakat yang semakin cerdas.

Dilihat dari motivasi kerja karyawan, yang pertama Kebutuhan Berkuasa (Need for Power), antara karyawan satu dengan yang lain cukup merespon untuk menjalankan ide-ide yang diusulkan oleh sesama karyawan dalam bekerja, Saya senang menjelaskan masalah pekerjaan kepada teman-teman sehingga mereka dapat menjalankan pekerjaan mereka dengan baik, Saya senang memberikan inspirasi produktif kepada teman-teman saya, Saya senang mengarahkan temanteman sehingga mereka bekerja lebih baik, Saya sering memberi arahan kepada teman-teman mengenai pekerjaan yang dilakukan. 


\section{KESIMPULAN, SARAN DAN KETERBATASAN}

\section{Kesimpulan}

Dari hasil analisis dapat disimpulkan bahwa :

1. Budaya di Sekretariat DPRD Gunung Kidul sudah mendorong pegawainya untuk inovatif, berani mengambil risiko, perhatian pada hal-hal yang detail, berfokus pada tim, mendorong pegawai umtuk tidak malas-malasan dan tidak mempertahankan status quo.

2. Faktor yang mendorong atau memotivasi karyawan untuk bekerja di Sekretariat DPRD Gunung Kidul adalah kebutuhan untuk berkuasa, kebutuhan berafilasi dan kebutuhan untuk berprestasi, dengan faktor yang paling dominan adalah kebutuhan untuk berafiliasi, diikuti kebutuhan kebutuhan berprestasi dan kebutuhan berkuasa.

3. Tidak terdapat perbedaan antara kinerja pada karyawan pria dan karyawan wanita.

4. Terdapat perbedaan antara variabel kebutuhan kekuasaan kelompok pada pria dan wanita.

5. Tidak terdapat perbedaan antara variabel kebutuhan berprestasi pada kelompok pria dan wanita.

6. Tidak terdapat perbedaan antara variabel kebutuhan berafiliasi pada kelompok pria dan wanita.

\section{SARAN}

1. Bagi kantor Sekretariat DPRD Kabupaten Gunung Kidul sekalipun hasil penelitian sudah mendorong pegawainya untuk inovatif, berani mengambil risiko, perhatian pada hal-hal yang detail, berfokus pada tim, mendorong pegawai umtuk tidak malas-malasan dan tidak mempertahankan status quo tetap harus lebih meningkatkan budaya inovatif karena era sekarang sekalipun ini kantor pemerintah budaya inovatif selalu ditingkatkan. 
2. Sekalipun kinerja pegawai sudah tinggi karyawan di Sekretariat DPRD Gunung Kidul harus tetap meningkatkan kinerja mereka karena mereka adalah sebagai abdi yang harus melayani masyarakat dengan baik.

\section{KETERBATASAN}

Dalam penelitian ini hanya menggunakan kuesioner tertutup sehingga kemungkinan banyak bias dalam menjawab untuk itu bagi peneliti berikutnya bisa ditambah dengan wawancara sehingga bisa menggali lebih jauh terkait dengan kinerja belum maksimal, motivasi untuk bergabung di organisasi.

\section{DAFTAR PUSTAKA}

Bass, B.M \& Avolio, 1993, Transformational Leadership and Organizational Culture, Public Administrasion Quarterly

-_-_-_-_ 1996, Does The Transactional-Transformational Leadership Paradigm Transcend Organizational and National Boundaries, Journal American Psychologist, 52: 130-139.

Bass, B.M. \& Seltzer, J. 1990. Transformational Leadership : Beyond Initiation and Consideration. Journal of Management. December, 693-703.

Caroline Pudjowibowo, Perbedaan Motivasi, Kepuasan Kerja, Keinginan berpindah kerja, dan Persepsi deskriminasi antara auditor pria dan wanita pada KAP di kota Semarang. Jurnal Akuntansi dan Bisnis, Vol.12 No.24 tahun 2014.

Djamaludin Ancok, 2012, Psikologi Kepemimpinan Inovasi, Erlangga, Jakarta

Gomez, L.E, 2010, Organizational Effectiveness, McGraw-Hill, New York

Imam, Ghozali, 2009, Aplikasi Analisis Multivariate dengan Program SPSS, Semarang: Badan Penerbit Universitas Diponegoro

Kreitner, Robert dan Angelo Kinichi. 2000. Organizational Behavior. Edisi ketiga USA D Irwin Inc.

Luthans, F, 2006, Perilaku Organisasi, Edisi Bahasa Indonesia,Edisi Sepuluh, Penerbit Andi.

Muslimin (2006),Perbedaan Gaya Kepemipinan dan Kinerja antara auditor pria dan wanita pada Kantor Akuntan Publik di Wilayah Surabaya Timur. Jurnal Ilmuilmu Ekonomi Vol 6 No.2 September 2006 : 86-93

Palupi, M \& Tjahjono,H.K. 2016. A Model of religiosity and organizational justice : the impact on Commitmen and dysfunctionalbehavior. Proceedings of the 27th IBIMA Conference.

Robbins, S.P.and Judge.T.A.2015. Perilaku Organisasi. Terjemahan Ratna Saraswati dan Febriella S. Jakarta Salemba Empat. 
Sekaran,U, 2013, Research Methods for Buiseness: a Skill-Building Approach, $6^{\text {rd }}$ edition, John Willey and Sons, Inc.

Satrio Makarawung, Analisis perbedaan Kinerja Karyawan berdasarkan Gaya kepemimpinan dan Budaya Organisasi pada PT Bank Sulut Cabang Kemungkinan dan PT Bank Sulut Capenrataka, Jurnal EMBA Vol.1 No.3 September 2013. Hal 326-333.

Tjahjono, H.K.2004. Budaya Organisasional dan Balanced Scoredard. UPFE UMY. 2015. Metode Penelitian Bisnis. VSM MM UMY

Tukijan dan Hasrnoto, Analisis perbedaan kecerdasan emosional, motivasi kerja dan kinerja ditinjau dari gender dan tingkat pendidikan (Studi Faskel Ekonomi PNPM mandiri Perkotaan Jawa Tengah), e-jurnal stieharmaputra.smg.ac.id/indexphp/JEMA/acticel/140/118 